\begin{abstract}
Title of Thesis:

PRESCHOOL IRRITABILITY PREDICTS ADOLESCENT PSYCHOPATHOLOGY AND FUNCTIONAL IMPAIRMENT: A 12-YEAR PROSPSECTIVE STUDY

Leah K. Sorcher

Master of Science, 2021

Thesis Directed By:

Professor Lea R. Dougherty

Department of Psychology
\end{abstract}

The long-term clinical and functional outcomes of preschool-age irritability are unknown. This study examined longitudinal associations of preschool irritability with psychiatric disorders and functional impairment in adolescence in a large community sample. 453 children were assessed at age three and at ages 12 and/or 15 . At age three, parents were interviewed about their child's irritability, psychiatric symptoms, and impairment. In adolescence, parents and youth were interviewed to assess youth psychopathology, depressive and anxiety symptoms, and impairment. Irritability at age three predicted internalizing and externalizing disorders in adolescence, parentreported anxiety and depressive symptoms, and greater functional impairment, including poorer peer functioning, physical health, and antidepressant and educational service use, even after controlling for baseline psychiatric disorders. All longitudinal associations persisted after further adjusting for well-established early life risk 
markers for psychopathology. Findings underscore the clinical significance and predictive power of preschool irritability and provide support for its use in intervention efforts. 


\title{
PRESCHOOL IRRITABILITY PREDICTS ADOLESCENT PSYCHOPATHOLOGY AND FUNCTIONAL IMPAIRMENT: A 12-YEAR PROSPECTIVE STUDY
}

\author{
by \\ Leah K. Sorcher \\ Thesis submitted to the Faculty of the Graduate School of the \\ University of Maryland, College Park, in partial fulfillment \\ of the requirements for the degree of \\ Master of Science \\ 2021
}

Advisory Committee:

Professor Lea R. Dougherty, Ph.D., Chair

Professor Andrea Chronis-Tuscano, Ph.D.

Karen Schwartz, Ph.D 
(C) Copyright by Leah K. Sorcher

2021 


\section{Table of Contents}

Table of Contents .............................................................................................. ii

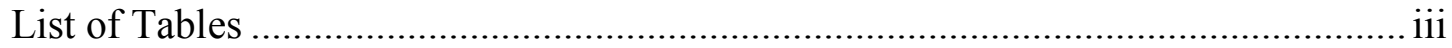

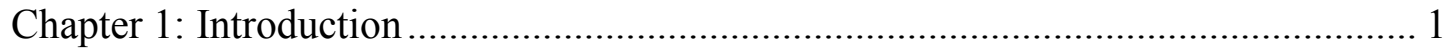

Chapter 2: Method .................................................................................................. 4

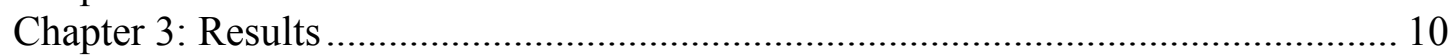

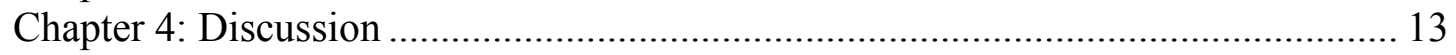

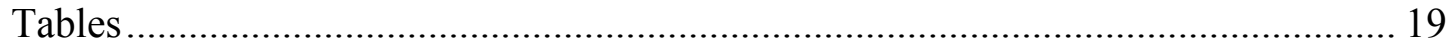

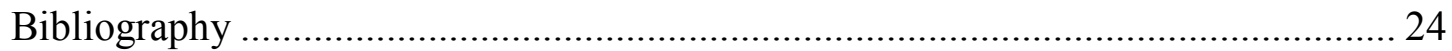

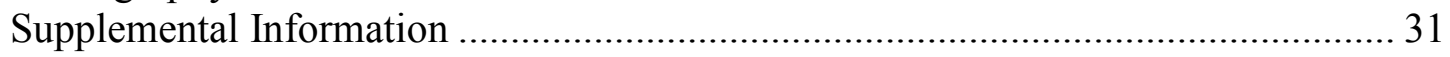




\section{List of Tables}

Table 1: Demographic and Clinical Characteristics of the Study Sample

Table 2: Irritability at Age 3 as Predictor of Adolescent Psychiatric Disorders

Table 3: Irritability at Age 3 as Predictor of Internalizing Symptoms at Age 15

Table 4: Irritability at Age 3 as Predictor of Functional Impairment, Suicidality and

Service Use at Age 15 


\section{Chapter 1: Introduction}

Irritability, characterized by low frustration tolerance and temper outbursts, is one of the most frequent reasons parents seek treatment for their children. ${ }^{1}$ Irritability is a transdiagnostic construct that cuts across multiple disorders, including major depressive disorder (MDD), generalized anxiety disorder (GAD), and oppositional defiant disorder (ODD), and is the cardinal feature of disruptive mood dysregulation disorder (DMDD). Youth irritability is associated with concurrent functional impairment even in the absence of psychiatric disorders. ${ }^{2,3}$ Irritability in school-aged children and adolescents predicts emotional disorders, specifically depressive and anxiety disorders, as well as ODD, suicidality, and greater overall functional impairment in adulthood. ${ }^{4-8}$ Consequently, there has been increasing focus and attention toward identifying irritability earlier in development.

Irritability is relatively common in early childhood. Nevertheless, recent evidence demonstrates that clinically significant irritability can be distinguished from normative levels and predicts psychiatric disorders and impairment in school-age children. ${ }^{9,10}$ Moreover, neural and behavioral correlates of preschool irritability are similar to findings in older youth, providing further validation of the construct and thus support for early childhood irritability as an important marker of risk. ${ }^{11-13}$ Establishing preschool irritability as an early predictive marker of risk across development is critical to its use in large-scale identification and intervention efforts. ${ }^{9}$

We have previously reported on the predictive validity of early childhood irritability in the Stony Brook Temperament Study, a large community-based longitudinal study that assessed children starting at age three. We found that irritability at age three predicted depression, ODD, and poorer functional impairment at age six, ${ }^{14}$ as well as anxiety disorders, including GAD and separation anxiety, functional impairment, and service use at age nine,,${ }^{15}$ over and above 
preschool (age 3) psychopathology. Preschool irritability also predicted mother and fatherreported (but not youth-reported) depressive and anxiety symptoms at age nine. Taken together, these findings demonstrate consistent associations with poor outcomes across early and middle childhood.

Prior work demonstrates that irritability in older youth and adolescents predicts depressive and anxiety disorders in adulthood, ${ }^{4,5}$ yet it is unknown whether the predictive capacity of preschool irritability stretches to internalizing disorders in adolescence. Additionally, it is unknown whether irritability is a unique predictor over and above other psychiatric problems. Thus, in the current report, we extend our prior findings to examine whether preschool irritability predicts adolescent psychopathology. Not only is the adolescent period a vulnerable time due to the rapid neuronal and maturational changes that occur, but it is also a time in which many forms of psychopathology become more prevalent and often predict continued maladjustment into adulthood. ${ }^{16}$ Moreover, adolescence is accompanied by new social stressors (e.g., academic, peer, and romantic stressors) that make it a particularly unique period of risk. Thus, understanding the links between early childhood irritability and adolescent outcomes will inform our understanding of psychopathology across the lifespan.

Our primary aim was to examine whether irritability assessed at age three predicts adolescent psychiatric disorders and outcomes, including functional impairment, medication and service use, physical health, and self-harm in unadjusted models and in models adjusting for demographic characteristics, pubertal status, and preschool psychopathology. We hypothesized that preschool irritability would predict depression, anxiety, and disruptive behavior disorders (DBD) in adolescence given that irritability shows strong associations with both internalizing and externalizing disorders. ${ }^{4,8,17}$ However, it was unclear whether irritability at age three would 
specifically predict attention-deficit/hyperactivity disorder (ADHD) given the limited and mixed findings in prior literature. ${ }^{8,14} \mathrm{We}$ also hypothesized that preschool irritability would continue to predict greater functional impairment and service use 12 years later over and above emotional or behavioral disorders at age three.

We further explored whether youth sex moderated associations between preschool irritability and adolescent outcomes. We previously reported sex differences in associations between preschool irritability and clinical outcomes in preadolescence (age 9): preschool irritability predicted anxiety disorders for boys only and ADHD for girls only at age nine. ${ }^{15} \mathrm{In}$ contrast, Humphreys et al. ${ }^{18}$ found that sex moderated the relation between irritability and concurrent and later internalizing symptoms for girls but not boys in adolescence. These findings suggest that sex differences in the associations between irritability and psychopathology may shift in adolescence when the sex difference in internalizing disorders emerges. ${ }^{19}$ Thus, we will explore whether the sex differences we observed in preadolescence persist or shift as children enter adolescence.

Finally, as a stringent test of the unique predictive validity of preschool irritability, we ran additional models adjusting for other well-established early-life markers of risk for later psychopathology, including parental depression history, early parenting, early child temperament, and preschool sleep problems. ${ }^{20,21}$ We hypothesized that the predictive power of preschool irritability would persist after adjusting for these other well-established markers of risk. 


\section{Chapter 2: Method}

\section{Participants}

Participants were from the Stony Brook Temperament Study, a longitudinal study investigating the role of early child temperament on the development of internalizing disorders (see Klein and Finsaas $^{22}$ ). Families $(N=541)$ participated in the baseline assessment at age three and were reassessed every three years at ages 6,9,12 and 15. The current manuscript focuses on outcomes in adolescence and only includes youth assessed at age three and ages 12 and/or 15 ( $n=453): 403$ youth participated at all 3 timepoints $(3,12$, and 15$) ; 50$ youth participated at baseline and only one of the adolescent assessments. The sample was largely non-Hispanic White (87\%), from two-parent (94\%), middle-class households at baseline (Hollingshead Four Factor Index of Social Status ${ }^{23} M=45.21, S D=10.93$ ); the majority of families had at least one parent with a 4-year college degree $(70.3 \%)$. See Table 1 for characteristics of the study sample.

Participants who completed both the age three and at least one of the adolescent assessments $(n=453)$ were compared to children who completed only the baseline assessment $(n=88)$ on age three variables. Children who participated at both the baseline and adolescent assessments were more likely to have a parent with a college education, $\chi^{2}(1, N=539)=7.21, p$ $=.007$, and to not have a diagnosis of social phobia at age three, $\chi^{2}(1, N=541)=5.37, p=.02$. No other significant differences were observed.

\section{Measures}

\section{Early Childhood Predictors}

Preschool Psychopathology. Parents (97.6\% mothers) were interviewed at age three with the Preschool Age Psychiatric Assessment (PAPA), ${ }^{24}$ a parent-report structured diagnostic interview. Interviews were conducted over the phone by graduate students in clinical 
psychology. Symptoms occurring three months prior to the interview were rated to maximize recall. Psychiatric disorders included any depressive disorder (MDD, dysthymic disorder, depressive disorder-not otherwise specified [NOS]); any anxiety disorder (specific phobia, separation anxiety disorder, social phobia, GAD, agoraphobia, selective mutism); ADHD, and ODD. Kappas were 1.00 for all diagnostic categories ( $n=21$ interviews independently coded by two raters). Symptom scales were created by summing the items in each diagnostic category excluding any irritability items to avoid overlap with the irritability scale (detailed below). For the non-overlapping symptom scales, the intraclass correlation coefficient (ICC) ranged from $.97-.99$ and the internal consistency $(\alpha)$ ranged from .54-.89.

Preschool Irritability. Six items from the PAPA were used to assess irritability: 1) irritable mood (depression section), 2) feelings of anger/bad temper under minor provocation (depression section), 3) displays of anger under minor provocation (depression section), 4) feelings of frustration under minor provocation (depression section), 5) discrete episodes of temper without violence (ODD section), and 6) discrete episodes of excessive temper, manifested by shouting, crying, or stamping, and/or involving violence/damage (ODD section). PAPA items were rated for intensity, frequency, and duration. Intensity ratings indicated whether a symptom was present or absent and the degree to which it was intrusive, interfering, and generalizable across activities. Following guidelines for chronic irritability from Brotman et al. ${ }^{4}$ and Copeland et al, ${ }^{2}$ items were coded as present if a child engaged in the behavior at least 45 times in the past three months. To assess whether the irritable mood state persisted for a clinically significant amount of time, the duration criterion was coded as present if the child was rated as having at least a 30-minute duration on irritable mood, prone to frustration, annoyance or anger, or difficulty recovering from temper tantrums. The total irritability scale $(\alpha=.73)$ 
consisted of the sum of symptoms coded as present according to the intensity, frequency, and duration criteria described above. These items did not overlap with items in the adolescent assessments.

Early Childhood Risk Factors. The Stony Brook Temperament Study includes a comprehensive evaluation of well-established early childhood risk factors assessed when children were three years old, including parental depression history, observed parental hostility, child temperament (negative and positive emotionality), and child sleep problems. ${ }^{22}$ See Supplement 1 for a description of these measures.

\section{Adolescent Outcomes}

Youth Psychiatric Disorders. At the age 12 and 15 assessments, one parent $(85.6 \%$ mothers at age 12 and $91.2 \%$ mothers at age 15) and the youth were interviewed using the Kiddie-Schedule of Affective Disorders and Schizophrenia-Present and Lifetime (K-SADSPL). ${ }^{25}$ Doctoral students in clinical psychology and a master's-level clinician, supervised by a child psychiatrist and clinical psychologist, administered the K-SADS first to the parent and then to the youth. Parent and youth reports were combined into summary ratings for each symptom. Current and interval DSM-IV diagnoses, present at any point during the assessment interval, were derived for the following psychiatric disorders: any depressive disorder (MDD, dysthymic disorder, depressive disorder-NOS); any anxiety disorder (specific phobia, social phobia, separation anxiety, GAD, agoraphobia, panic, obsessive compulsive, post-traumatic stress, and acute stress disorder, anxiety disorder-NOS); any DBD (ODD, conduct disorder, DBD-NOS); and any ADHD (ADHD-inattentive, hyperactivity or combined type, ADHD-NOS). For the current manuscript, we used data from the age 12 and 15 clinical interviews that covered the period across the transition to adolescence starting after the age nine assessment through age 15 
and therefore do not overlap with data in Dougherty et al. ${ }^{15}$ To assess interrater reliability, a second rater independently derived ratings from videotapes for 25 participants. Kappas for adolescent diagnoses ranged from .72-1.00.

Youth Current Depressive and Anxiety Symptoms. At age 15, 418 mothers $(\alpha=.81)$ and 356 fathers $(\alpha=.76)$ completed the 17-item parent version of the Child Depression Inventory (CDI-2) $)^{26}$ and 412 youth $(\alpha=.83)$ completed the 28 -item youth report version to assess current depressive symptoms. Additionally, 418 mothers $(\alpha=.91), 355$ fathers $(\alpha=.90)$, and 410 youth $(\alpha=.93)$ completed the 41-item Screen for Child Anxiety Related Disorders (SCARED) ${ }^{27}$ to assess anxiety symptoms. Total scores were derived and analyzed separately for mother, father, and youth-reported CDI and SCARED variables. Correlations between maternal and paternalreported CDI and SCARED scores were .54 and .55 , respectively, and correlations ranged from .30 to .44 between either maternal or paternal and youth reports.

Current Functional Impairment. The K-SADS interviewer completed the Children's Global Assessment Scale (C-GAS) ${ }^{28}$ following the administration of the K-SADS at age 15 with both the youth and parent. The C-GAS is a global measure of children's level of functioning. Scores range from $0-100$, where 0 indicates the worst functioning and 100 indicates superior functioning $(\mathrm{ICC}=.77)$. At age 15, youth also completed the UCLA Life Stress Interview $(\mathrm{LSI}),{ }^{29}$ a semi-structured interview that includes ratings of chronic stress in multiple domains: academic and behavioral, peer, and family. These chronic stress scores can also be interpreted as reflecting levels of social functioning where higher levels of stress indicate poorer functioning. ${ }^{30}$ Scores from the academic and school behavioral sections were averaged to create the Academic and Behavioral Stress score, which consisted of items reflecting performance in classes, degree of difficulty with and extra help needed for schoolwork, and problems with teachers and peers at 
school. The Peer Stress score consisted of items from the close friends and social sections, such as number of close friends, conflict, bullying, and degree of popularity/social engagement. The Family Stress score contained items from the family section and assessed quality of relationships with family members and degree of family support, tension, and conflict. Ratings were assigned on a scale from 1 to 5 ; higher scores reflect poorer functioning. ICC's ranged from .75 to .92 ( $n=30$ recorded interviews rated by two independent raters).

Treatment and Suicidality. At age 15, the K-SADS interviewer assessed whether youths were prescribed psychotropic medication, received educational and/or psychiatric treatment services, including outpatient services and hospitalizations, and/or if they had exhibited suicidal ideation or non-suicidal self-injurious behavior. Based on parent and youth report, items were rated as present if the youth received services or exhibited these symptoms in the period after the age 12 assessment through the age 15 assessment.

Physical Health. Youth completed the perceived physical health scale from The Oregon Adolescent Depression Project (OADP) ${ }^{31}$ a one-item measure rated on a 5-point scale where higher scores indicate worse health. Youth also completed the Pubertal Development Scale $(\mathrm{PDS})^{32}$ at the age 15 assessment.

\section{Data Analyses}

Binary logistic regression analyses were conducted to examine longitudinal associations between preschool irritability and adolescent psychiatric diagnoses (depressive disorder, anxiety disorder, $\mathrm{DBD}$, and $\mathrm{ADHD}$ ). Odds ratios (OR) provide the effect size estimate. Separate models were run for each of the four diagnoses. We also examined associations between preschool irritability and specific phobia, social phobia, separation anxiety and GAD in adolescence given longitudinal associations between irritability and specific anxiety disorders. ${ }^{5,15}$ The irritability 
measure was standardized (z-score) and entered as the independent variable. Linear regression analyses were used to examine longitudinal associations between preschool irritability and psychiatric symptom scales at age 15 . We report unadjusted models, models adjusted for covariates (youth's current age, pubertal status, biological sex, and parental education) and models adjusted for covariates and the corresponding psychiatric disorder at age three.

Linear regression analyses were used to examine longitudinal associations between preschool irritability and functional impairment ratings and youth-reported physical health at age 15. Logistic regression analyses were used to examine longitudinal associations between preschool irritability and psychotropic medication use, psychiatric treatment and educational services, suicidal ideation, and non-suicidal self-injurious behavior. We report unadjusted models, models adjusted for covariates, and models adjusted for covariates and the presence of any age three emotional or behavioral disorder. Further, all logistic and linear regression analyses were rerun with preschool irritability, sex, and an irritability $\mathrm{X}$ sex interaction term entered as independent variables to explore whether sex moderated associations between preschool irritability and adolescent outcomes.

Lastly, we examined whether preschool irritability would continue to predict adolescent outcomes even after accounting for well-established markers of early life risk, including parental depression, parental hostility, child temperament, and child sleep problems. All linear and logistic regression analyses were rerun as separate models with these variables as additional covariates. 


\section{Chapter 3: Results}

\section{Preschool Irritability as Predictor of Adolescent Psychiatric Disorders}

Table 2 shows associations between preschool irritability and adolescent psychiatric disorders, unadjusted and adjusted for covariates and corresponding age three disorders. After controlling for covariates and corresponding baseline disorders, preschool irritability predicted any anxiety disorder, specific phobia, social phobia, GAD, ADHD, and DBD in adolescence but not depression. Results were similar across the age 12 and age 15 assessments (see Table S1, available online). Further, a multinomial logistic regression revealed that preschool irritability predicted internalizing and externalizing comorbidity $(\mathrm{OR}=1.67, \mathrm{CI}=1.22-2.28, p=.001)$.

\section{Preschool Irritability as Predictor of Current Internalizing Symptoms at Age 15}

Table 3 shows associations between irritability at age three and youth's current depressive and anxiety symptoms, unadjusted and adjusted for covariates and the corresponding age three symptom scales. In unadjusted models and models adjusting for covariates, preschool irritability significantly predicted maternal and paternal-reported CDI and SCARED total scores at age 15. After further adjusting for the corresponding symptom scales at age 3, all associations remained significant except for paternal-reported SCARED. Irritability did not predict youthreported values.

\section{Preschool Irritability as Predictor of Adolescent Impairment and Service Use Outcomes}

In unadjusted models, preschool irritability predicted lower C-GAS scores, poorer peer functioning and physical health, non-suicidal self-injurious behavior, psychiatric treatment services, psychotropic medication use, and educational services in adolescence (Table 4). After adjusting for covariates, preschool irritability continued to predict all outcomes except for psychotropic medication use. We then further controlled for any emotional or behavioral 
disorders at age three and preschool irritability remained a unique predictor of poorer peer functioning and physical health at age 15 as well as educational service use, with trend-level associations for psychiatric treatment services and non-suicidal self-injurious behavior. Given initial associations with psychotropic medication use, we additionally examined whether preschool irritability predicted specific classes of drugs in our sample and found associations between preschool irritability and antidepressant use $(\mathrm{OR}=2.69, \mathrm{CI}=1.22-5.91, p=.01)$, which persisted after controlling for covariates and any emotional/behavioral disorder at age three.

\section{Sex Differences}

Child sex moderated the longitudinal association between preschool irritability and a diagnosis of $\mathrm{ADHD}$ in adolescence $(\mathrm{OR}=.38, \mathrm{CI}=.22-.66, p=.001)$, controlling for covariates and age 3 ADHD. Preschool irritability predicted adolescent ADHD for girls $(\mathrm{OR}=2.54, \mathrm{CI}=1.61$ $4.02, p<.001)$ but not boys $(\mathrm{OR}=.98, \mathrm{CI}=.73-1.31, p=.87)$. Additionally, child sex moderated the longitudinal association between preschool irritability and psychotropic medication use at age 15 $(\mathrm{OR}=.56, \mathrm{CI}=.33-.95, p=.03)$, controlling for covariates and baseline emotional/behavioral disorders. Preschool irritability predicted psychotropic medication use at age 15 for girls $(\mathrm{OR}=1.72, \mathrm{CI}=1.11-2.68, p=.02)$ but not boys $(\mathrm{OR}=.97, \mathrm{CI}=.69-1.35, p=.84)$.

\section{Additional Analyses}

Specificity Analyses. All longitudinal associations between preschool irritability and adolescent outcomes persisted after further adjusting for well-established early life risk markers for psychopathology: parental depression history, observed parental hostility, observed child temperamental negative emotionality and positive emotionality, and interviewer-rated child sleep problems, all assessed at age 3 (see Supplement 1). 
Non-linear Associations. Given prior work that suggested non-linear associations between irritability and neurobiological measures ${ }^{33}$ we re-ran models presented above with additional curvilinear terms (quadratic and cubic); no associations were significant.

Assumptions. We checked the skew and kurtosis values for all variables used in linear regression analyses; square root transformations normalized data for variables that demonstrated positive skew. All results were similar with transformed variables; we report analyses using raw scores for ease of interpretability. 


\section{Chapter 4: Discussion}

We examined longitudinal associations between preschool irritability and adolescent outcomes in a large, community-based sample. We found that irritability at age three predicted adolescent anxiety disorders, including specific phobia, social phobia, and GAD, and ADHD and DBD, even after controlling for baseline psychiatric disorders. Consistent with our prior findings in preadolescence, preschool irritability predicted depressive and anxiety symptoms on maternal and paternal reports, but not youth reports. Similarly, preschool irritability predicted greater functional impairment, including poorer peer functioning and physical health in adolescence as well as greater likelihood of non-suicidal self-injury and use of psychiatric treatment and educational services. Further, early childhood irritability continued to predict all adolescent outcomes even after accounting for other well-established markers of early life risk, providing convincing evidence for its incremental utility in large-scale identification and intervention efforts.

Many associations with adolescent psychopathology were consistent with our findings in preadolescence; thus, we did not observe major changes as youth entered adolescence. However, there were some differences between preadolescence and our current findings. Preschool irritability predicted both internalizing and externalizing disorders and their co-occurrence in adolescence whereas at age 9 preschool irritability only predicted anxiety disorders. These findings are in line with previous work in older youth that show irritability is concurrently ${ }^{2}$ and longitudinally ${ }^{34}$ associated with emotional and behavioral disorders in adolescence. There has been growing interest in identifying potential underlying mechanisms through which early irritability leads to these diverse outcomes. Beauchaine and Constantino ${ }^{35}$ hypothesized that variations in biological systems may determine whether irritability is expressed in a more 
externalizing or internalizing manner. Consistent with this hypothesis, in the current sample, Kessel et al. ${ }^{36}$ examined whether error related negativity at age six $(\Delta \mathrm{ERN})$, a neural marker of error monitoring, as well as diurnal cortisol slope at age 9 , a measure of stress system functioning, ${ }^{37}$ differentiated internalizing vs. externalizing pathways. In children with high levels of irritability at age three, an enhanced $\triangle E R N$ at age six predicted internalizing disorders at age nine and a steeper diurnal cortisol slope at age nine predicted greater internalizing symptoms at age 12; a smaller $\triangle E R N$ predicted externalizing disorders at age nine while a blunted cortisol slope at age nine predicted greater externalizing symptoms at $12 .{ }^{36,37}$ It will be important for future work in this sample and other samples to identify factors that differentiate developmental trajectories from early irritability to later internalizing versus externalizing outcomes.

Although preschool irritability did not predict depressive disorders in adolescence, it predicted subthreshold depressive symptoms based on parent report using dimensional measures of symptomatology. It is important to note that our sample was only 15 , which is still at the beginning of the period of risk for developing depression. Nevertheless, subthreshold depressive disorder in adolescence is one of the strongest predictors for the onset of full-syndrome depressive disorders in adulthood. ${ }^{38}$ Likewise, preschool irritability predicted adolescent anxiety disorders as well as externalizing diagnoses (DBD and ADHD), and prior work demonstrates that both anxiety and externalizing problems predict depression in adulthood. ${ }^{39}$ Thus, it will be important for our future work to test whether preschool irritability predicts the subsequent development of depressive disorders in emerging adulthood and whether adolescent subthreshold depressive symptoms, anxiety, and externalizing problems are involved in this developmental progression. 
Associations between preschool irritability and current depressive and anxiety symptoms in adolescence demonstrated discrepancies between parent and child reports, with youth report showing no associations. There is general consensus that agreement on informant ratings in adolescence is low, ${ }^{40}$ suggesting that youth and parent reports may be capturing different aspects of the youth's emotional experience. ${ }^{5}$ Our findings could be due to shared method variance; nevertheless, psychopathology in adolescence was assessed by interviewing both the parent and youth and we found significant associations between irritability and maternal- and paternalreported symptoms, thus potentially limiting that confound. It is also possible that parent and youth reports of internalizing symptoms are capturing different symptoms. For instance, some internalizing symptoms may be more salient to the youth experiencing the symptoms (e.g., feelings of sadness, worry) whereas other symptoms may be more salient to those interacting with the youth (e.g., grumpiness, withdrawal) ${ }^{41}$ Thus, future work should consider how these constructs may differ depending on the reporter and across development.

Preschool irritability also predicted greater functional impairment in adolescence, including poorer peer functioning and physical health, and greater likelihood of non-suicidal self-injury and use of psychiatric treatment, psychotropic medications, and educational services. Associations with peer functioning, physical health, and antidepressant and educational service use persisted even after adjusting for covariates and preschool emotional or behavioral disorders. Although preschool irritability only exhibited trend-level associations with non-suicidal selfinjury after controlling for both covariates and age three psychopathology, links between nonsuicidal self-injury and irritability in children have been reported. ${ }^{42}$ Further, irritability in older children is a strong predictor of increased suicidal behaviors in adolescence and adulthood, including suicidal ideation and attempts. ${ }^{43}$ While these types of self-harm behaviors were rare in 
the current sample, associations may strengthen later in adolescence as self-harm behaviors become more prevalent. ${ }^{44}$ Additionally, we found that preschool irritability predicted adolescent's antidepressant use. This should be interpreted with caution as the association was only based on 18 youth; however, this too points to the importance of examining irritability and the development of depressive disorders in emerging adulthood.

We further found that child sex moderated the longitudinal associations between preschool irritability and ADHD and psychotropic medication use in adolescence for girls but not boys. These results are likely related as $72.7 \%$ of youth taking psychotropic medication also had a diagnosis of ADHD. With regard to ADHD, our findings replicate the results reported prior to adolescence in the current sample,${ }^{15}$ providing convincing evidence that this is an important effect. Since girls with ADHD are more likely to develop depression in adolescence and adulthood, ${ }^{45}$ it will be important for future work to consider the role of early irritability in this later association. Additionally, given that ADHD is significantly harder to detect in preschool-age children due to developmental constraints, identifying preschool irritability in girls could be a good indicator to recommend further testing for ADHD as they get older.

Although we found two sex-specific associations, on the whole we generally did not find sex differences. Irritability seems to be impacting both boys and girls in similar ways, which is in line with findings that show few sex differences in the phenomenology of irritability. ${ }^{18,46}$

Finally, preschool irritability continued to predict all adolescent outcomes over and above well-established markers of early-life risk, including parental depression history, parental hostility, child temperament, and child sleep problems. These findings add to the mounting evidence that preschool irritability may be useful as an early life marker for early identification and prevention. Having a targeted construct for intervention and treatment would help to reduce 
the societal burden and public health implications of irritability, as well as all its associated negative outcomes, in adulthood.

This study had several strengths, including the use of a large community sample of preschoolers that were followed to age 15 (span of 12 years thus far) and comprehensive clinical assessments and measures of early life risk over time using a multi-method, multi-informant approach. The study also had its limitations. First, our sample was largely White and middle class and thus not generalizable to diverse samples. Second, we did not correct for multiple comparisons as we viewed our analyses as exploratory and intended for future hypothesis generation. Third, although we took into account the frequency of irritability in the early childhood period, we used DSM cutoffs for clinically-significant irritability rather than empirically-based cutoffs. ${ }^{10}$ Fourth, our measure of preschool irritability did not examine different aspects of irritability. While it is possible that irritability may reflect a nonspecific liability to develop psychopathology, there is growing evidence that irritability in older youth and adolescents can be parsed into tonic (irritable, touchy mood) and phasic (temper outbursts) components, which may predict different clinical outcomes. ${ }^{47,48}$ Distinguishing types of irritability may have important clinical relevance as phasic irritability often drives clinical referrals and critical treatment decisions. ${ }^{47}$ Irritability may also be further parsed (e.g., by context of other impairments or setting $)^{47}$ in ways that could similarly explain its multifinality. Thus, research is needed to determine whether these components can be parsed in early childhood and if so whether they predict similar or different outcomes. Lastly, future work should examine the structure of preschool psychopathology using transdiagnostic hierarchical approaches, such as the Hierarchical Taxonomy of Psychopathology (HiTOP), ${ }^{49}$ to identify the placement of irritability and its specificity in predicting later clinical outcomes. 
In summary, our findings underscore the clinical significance and predictive validity of early childhood irritability. Preschool irritability predicted internalizing and externalizing disorders in adolescence, parent-reported anxiety and depressive symptoms, and greater functional impairment, even after controlling for baseline psychiatric disorders. Importantly, the effects of preschool irritability persisted after adjusting for other well-established markers of early life risk. These findings strongly support the need for early identification of irritability in young children and the importance of intervening as early as possible. Further, investigating the mechanisms by which preschool irritability leads to such widespread impairment and develops into adolescent and adult phenotypes is paramount to aid in determining treatment targets and approaches. 


\section{Tables}

Table 1: Demographic and Clinical Characteristics of the Study Sample

\begin{tabular}{|c|c|c|c|c|c|c|}
\hline \multirow{2}{*}{ Demographic Characteristics } & \multicolumn{3}{|c|}{ Age 3} & \multicolumn{3}{|c|}{ Age 15} \\
\hline & & & & & & \\
\hline Child mean age: years (SD) & 3.51 & $(.26)$ & & 15.25 & $(.40)$ & \\
\hline Child sex: female $n(\%)$ & 212 & $(46.8)$ & & & & \\
\hline \multicolumn{7}{|l|}{ Child race: $n(\%)$} \\
\hline White & 428 & $(94.5)$ & & & & \\
\hline Black/African American & 11 & $(2.4)$ & & & & \\
\hline Asian & 11 & $(2.4)$ & & & & \\
\hline Other & 3 & $(.6)$ & & & & \\
\hline Child Hispanic ethnicity: $n(\%)$ & 40 & $(8.8)$ & & & & \\
\hline \multicolumn{7}{|l|}{ Biological parents' marital status: $n(\%)$} \\
\hline Married & 426 & $(94.2)$ & & & & \\
\hline Divorced, separated, or widowed & 12 & $(2.7)$ & & & & \\
\hline Never married & 14 & (3.1) & & & & \\
\hline \multicolumn{7}{|l|}{ Parents' education: graduated college $n(\%)$} \\
\hline Mother & 259 & $(58.1)$ & & & & \\
\hline Father & 210 & $(47.7)$ & & & & \\
\hline $\begin{array}{l}\text { Mean child irritability at age } 3 \text { (0-7) (SD; } \\
\text { range) }\end{array}$ & .72 & $(1.33)$ & $0-7$ & & & \\
\hline \multicolumn{7}{|l|}{ Youth psychopathology $n(\%)^{\mathrm{a}}$} \\
\hline Depressive Disorder & 8 & $(1.8)$ & & 69 & $(15.3)$ & \\
\hline Anxiety Disorder & 90 & (19.9) & & 111 & $(24.6)$ & \\
\hline Specific Phobia & 44 & $(9.7)$ & & 56 & (12.4) & \\
\hline Social Phobia & 16 & (3.5) & & 33 & $(7.3)$ & \\
\hline Separation Anxiety & 27 & $(6.0)$ & & 16 & $(3.5)$ & \\
\hline GAD & 20 & $(4.4)$ & & 36 & $(8.0)$ & \\
\hline ADHD & 9 & $(2.0)$ & & 77 & $(17.1)$ & \\
\hline ODD & 45 & $(9.9)$ & & 19 & $(4.2)$ & \\
\hline DBD & -- & & & 30 & $(6.7)$ & \\
\hline \multicolumn{7}{|l|}{$\begin{array}{l}\text { Mean youth symptom scales at age } 15(\mathrm{SD} \text {; } \\
\text { range) }\end{array}$} \\
\hline Maternal-reported CDI-2 & & & & 7.94 & $(5.41)$ & $0-34$ \\
\hline Paternal-reported CDI-2 & & & & 8.11 & $(5.07)$ & $0-36$ \\
\hline Youth-reported CDI-2 & & & & 6.10 & $(5.49)$ & $0-29$ \\
\hline Maternal-reported SCARED & & & & 6.53 & $(7.25)$ & $0-41$ \\
\hline Paternal-reported SCARED & & & & 6.11 & $(6.67)$ & $0-46$ \\
\hline Youth-reported SCARED & & & & 16.75 & (11.83) & $0-57$ \\
\hline \multicolumn{7}{|l|}{ Suicidality by age $15 n$ (\%) } \\
\hline Non-Suicidal Self Injury & & & & 26 & $(6.2)$ & \\
\hline Suicidal Ideation & & & & 33 & $(7.8)$ & \\
\hline \multicolumn{7}{|l|}{ Youth functioning at age 15} \\
\hline C-GAS (SD; range) & & & & 78.75 & (11.44) & $0-97$ \\
\hline
\end{tabular}


LSI Academic and Behavioral Functioning $^{\mathrm{b}}$

LSI Peer Functioning ${ }^{b}$

LSI Family Functioning ${ }^{\mathrm{b}}$

Treatment and Services $n(\%)$

Outpatient treatment services

Hospitalized

Educational Services

Psychotropic medication use

ADHD medications

Antidepressants

Anxiolytics

Antipsychotics

Clonidine

Mood stabilizer

Physical Health at age 15

Youth-reported Physical Health

Youth-reported Pubertal Development
$1.51 \quad(.47)$

$1-3.75$

$2.17 \quad(.50)$

$1-4.25$

$2.12 \quad(.48)$

$1.5-4.0$

$106 \quad(25.2)$

$5 \quad(1.2)$

$48 \quad(11.4)$

$66 \quad(15.7)$

$35 \quad(7.7)$

$18 \quad(4.0)$

$6 \quad(1.3)$

$5 \quad(1.1)$

$1 \quad(0.2)$

$1 \quad(0.2)$

$1.92 \quad(.79) \quad 1-5$

$15.17 \quad(2.18) \quad 5-20$

Scale

Note: $n=453 ; 451$ children completed the K-SADS only. ADHD=attention-deficit/hyperactivity disorder; CDI-2=Child Depression Inventory-2; CGAS=Children's Global Assessment Scale; $\mathrm{DBD}=$ disruptive behavior disorder; $\mathrm{DMDD}=$ disruptive mood dysregulation disorder; $\mathrm{GAD}=$ generalized anxiety disorder; $\mathrm{LSI}=$ Life Stress Interview; ODD=oppositional defiant disorder; SCARED=Screen for Child Anxiety Related Disorders; SD=standard deviation.

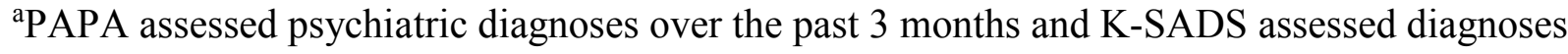
at ages 12 and 15 that reflect the presence of diagnoses in the three years prior.

${ }^{\mathrm{b}}$ Higher scores indicate poorer functioning. 
Table 2: Irritability at Age 3 as Predictor of Adolescent Psychiatric Disorders

\section{Age 3 Irritability}

\begin{tabular}{|c|c|c|c|c|c|c|}
\hline & \multicolumn{2}{|c|}{ Not Adjusted } & \multicolumn{2}{|c|}{$\begin{array}{l}\text { Adjustment for } \\
\text { Covariates }\end{array}$} & \multicolumn{2}{|c|}{$\begin{array}{l}\text { Adjustment for Covariates } \\
\text { and Corresponding } \\
\text { Disorder at Age } 3\end{array}$} \\
\hline $\begin{array}{l}\text { Psychiatric } \\
\text { Disorder }\end{array}$ & $\begin{array}{l}\text { Odds } \\
\text { Ratio }\end{array}$ & $95 \%$ CI & $\begin{array}{l}\text { Odds } \\
\text { Ratio }\end{array}$ & $95 \%$ CI & $\begin{array}{l}\text { Odds } \\
\text { Ratio }\end{array}$ & $95 \% \mathrm{CI}$ \\
\hline $\begin{array}{l}\text { Depressive } \\
\text { Disorder }\end{array}$ & .97 & $.75-1.25$ & 1.08 & $.82-1.43$ & 1.10 & $.83-1.46$ \\
\hline $\begin{array}{l}\text { Anxiety } \\
\text { Disorder }\end{array}$ & $1.29 * *$ & $1.07-1.57$ & $1.42 * *$ & $1.15-1.77$ & $1.41 * *$ & $1.13-1.77$ \\
\hline $\begin{array}{l}\text { Specific } \\
\text { Phobia }\end{array}$ & $1.36 * *$ & $1.08-1.71$ & $1.47 * *$ & $1.15-1.89$ & $1.47 * *$ & $1.14-1.89$ \\
\hline $\begin{array}{l}\text { Social } \\
\text { Phobia }\end{array}$ & $1.34^{*}$ & $1.01-1.77$ & $1.51 * *$ & $1.12-2.04$ & $1.51 * *$ & $1.12-2.04$ \\
\hline $\begin{array}{l}\text { Separation } \\
\text { Anxiety }\end{array}$ & 1.28 & $.86-1.90$ & 1.10 & $.63-1.92$ & 1.08 & $.60-1.95$ \\
\hline GAD & $1.31^{\dagger}$ & $1.00-1.73$ & $1.41^{*}$ & $1.04-1.92$ & $1.46^{*}$ & $1.06-2.01$ \\
\hline ADHD & $1.35^{* *}$ & $1.10-1.67$ & $1.30 *$ & $1.03-1.65$ & $1.28 *$ & $1.00-1.64$ \\
\hline $\mathrm{DBD}$ & $1.92 * * *$ & $1.48-2.50$ & $2.16^{* * *}$ & $1.59-2.95$ & $2.40 * * *$ & $1.60-3.60$ \\
\hline
\end{tabular}

Note: Covariates include current age, youth sex, parental education, and youth-rated Pubertal Development Scale. K-SADS assessed diagnoses at ages 12 and 15 that reflect the presence of diagnoses in the three years prior. $\mathrm{ADHD}=$ attention-deficit/hyperactivity disorder; $\mathrm{CI}=$ Confidence Interval; $\mathrm{DBD}=$ disruptive behavior disorder; $\mathrm{GAD}=$ generalized anxiety disorder. ${ }^{\dagger} p<.10 ; * p<.05 ; * * p<.01 ; * * * p<.001$. 
Table 3: Irritability at Age 3 as Predictor of Internalizing Symptoms at Age 15

\begin{tabular}{|c|c|c|c|c|c|c|}
\hline \multirow[b]{3}{*}{$\begin{array}{l}\text { Symptoms } \\
\text { at age } 15\end{array}$} & \multicolumn{6}{|c|}{ Age 3 Irritability } \\
\hline & \multicolumn{2}{|c|}{ Not Adjusted } & \multicolumn{2}{|c|}{$\begin{array}{l}\text { Adjustment for } \\
\text { covariates }\end{array}$} & \multicolumn{2}{|c|}{$\begin{array}{c}\text { Adjustment for covariates } \\
\text { and corresponding age } 3 \\
\text { symptom scale }\end{array}$} \\
\hline & B & B(SE) & B & B(SE) & B & B(SE) \\
\hline $\begin{array}{l}\text { Maternal- } \\
\text { reported } \\
\text { CDI-2 }\end{array}$ & $.27 * * *$ & $1.45(.26)$ & $.26^{* * *}$ & $1.38(.26)$ & $.21 * * *$ & $1.11(.28)$ \\
\hline $\begin{array}{l}\text { Paternal- } \\
\text { reported } \\
\text { CDI-2 }\end{array}$ & $.14 * *$ & $.70(.27)$ & $.13^{*}$ & $.66(.28)$ & $.12 *$ & $.62(.31)$ \\
\hline $\begin{array}{l}\text { Youth- } \\
\text { reported } \\
\text { CDI-2 }\end{array}$ & .03 & $.16(.28)$ & .07 & $.41(.27)$ & .05 & $.30(.30)$ \\
\hline $\begin{array}{l}\text { Maternal- } \\
\text { reported } \\
\text { SCARED }\end{array}$ & $.19 * * *$ & $1.41(.35)$ & $.23 * * *$ & $1.73(.36)$ & $.19 * * *$ & $1.41(.38)$ \\
\hline $\begin{array}{l}\text { Paternal- } \\
\text { reported } \\
\text { SCARED }\end{array}$ & $.15^{* *}$ & $1.02(.35)$ & $.16^{* *}$ & $1.06(.36)$ & $.10^{\dagger}$ & $.70(.39)$ \\
\hline $\begin{array}{l}\text { Youth- } \\
\text { reported } \\
\text { SCARED }\end{array}$ & -.01 & $-.15(.60)$ & .03 & $.36(.57)$ & -.01 & $-.16(.63)$ \\
\hline
\end{tabular}

Note: Covariates include current age, youth sex, parental education, and youth-rated Pubertal Development Scale. CDI-2=Child Depression Inventory-2; SCARED=Screen for Child Anxiety Related Disorders.

${ }^{\dagger} p<.10,{ }^{*} p<.05, *^{*} p<.01, * * * p<.001$. 
Table 4: Irritability at Age 3 as Predictor of Functional Impairment, Suicidality and Service Use at Age 15

\begin{tabular}{|c|c|c|c|c|c|c|}
\hline & \multicolumn{6}{|c|}{ Age 3 Irritability } \\
\hline & \multicolumn{2}{|c|}{ Not adjusted } & \multicolumn{2}{|c|}{$\begin{array}{l}\text { Adjustment for } \\
\text { covariates }\end{array}$} & \multicolumn{2}{|c|}{$\begin{array}{c}\text { Adjustment for } \\
\text { covariates and age } 3 \\
\text { psychopathology }\end{array}$} \\
\hline $\begin{array}{l}\text { Age } 15 \\
\text { Outcomes }\end{array}$ & B & B(SE) & B & B(SE) & B & $\mathrm{B}(\mathrm{SE})$ \\
\hline C-GAS & $-.16^{* *}$ & $-1.76(.52)$ & $-.13 * *$ & $-1.45(.54)$ & -.08 & $-.90(.59)$ \\
\hline $\begin{array}{l}\text { LSI Academic/ } \\
\text { Behavioral } \\
\text { Functioning }\end{array}$ & -.004 & $-.002(.02)$ & -.05 & $-.02(.02)$ & -.07 & $-.03(.03)$ \\
\hline $\begin{array}{l}\text { LSI Peer } \\
\text { Functioning }\end{array}$ & $.14^{* *}$ & $.07(.03)$ & $.14^{* *}$ & $.07(.03)$ & $.13^{*}$ & $.07(.03)$ \\
\hline $\begin{array}{l}\text { LSI Family } \\
\text { Functioning }\end{array}$ & -.03 & $-.02(.03)$ & -.004 & $-.002(.03)$ & -.04 & $-.02(.03)$ \\
\hline \multirow[t]{2}{*}{$\begin{array}{l}\text { Youth-reported } \\
\text { Physical Health }\end{array}$} & $.11^{*}$ & $.08(.04)$ & $.11^{*}$ & $.09(.04)$ & $.11^{*}$ & $.09(.05)$ \\
\hline & OR & $95 \% \mathrm{CI}$ & OR & $95 \% \mathrm{CI}$ & OR & $95 \% \mathrm{CI}$ \\
\hline $\begin{array}{l}\text { Non-Suicidal } \\
\text { Self-Injury }\end{array}$ & $1.37^{*}$ & $1.00-1.88$ & $1.51 *$ & $1.08-2.12$ & $1.39^{\dagger}$ & $.95-2.03$ \\
\hline $\begin{array}{l}\text { Suicidal } \\
\text { Ideation }\end{array}$ & 1.12 & $.82-1.56$ & 1.32 & $.93-1.90$ & 1.24 & $.83-1.83$ \\
\hline $\begin{array}{l}\text { Psychiatric } \\
\text { Treatment } \\
\text { Services }\end{array}$ & $1.28 *$ & $1.05-1.57$ & $1.29 *$ & $1.04-1.60$ & $1.26^{\dagger}$ & $.99-1.59$ \\
\hline $\begin{array}{l}\text { Educational } \\
\text { Services }\end{array}$ & $1.36^{*}$ & $1.06-1.74$ & $1.32 *$ & $1.01-1.73$ & $1.51 * *$ & $1.11-2.04$ \\
\hline $\begin{array}{l}\text { Psychotropic } \\
\text { medication }\end{array}$ & $1.29 *$ & $1.03-1.62$ & 1.21 & $.94-1.55$ & 1.15 & $.87-1.51$ \\
\hline
\end{tabular}

Note: Covariates include current age, gender, parental education, and youth-rated Pubertal Development Scale. CGAS=Children's Global Assessment Scale; CI=Confidence Interval; $\mathrm{OR}=$ Odds Ratio; $\mathrm{SE}=$ Standard Error. ${ }^{\dagger} p<.10, * p<.05, * * p<.01, * * * p<.001$. 


\section{Bibliography}

1. Brotman MA, Kircanski K, Leibenluft E. Irritability in Children and Adolescents. Annu Rev Clin Psychol. Published online 2017. doi:10.1146/annurev-clinpsy-032816-044941

2. Copeland WE, Angold A, Costello EJ, Egger H. Prevalence, comorbidity, and correlates of DSM-5 proposed disruptive mood dysregulation disorder. Am J Psychiatry. Published online 2013. doi:10.1176/appi.ajp.2012.12010132

3. Stringaris A, Goodman R. Mood lability and psychopathology in youth. Psychol Med. Published online 2009. doi:10.1017/S0033291708004662

4. Brotman MA, Schmajuk M, Rich BA, et al. Prevalence, Clinical Correlates, and Longitudinal Course of Severe Mood Dysregulation in Children. Biol Psychiatry. Published online 2006. doi:10.1016/j.biopsych.2006.08.042

5. Stringaris A, Cohen P, Pine DS, Leibenluft E. Adult outcomes of youth irritability: A 20year prospective community-based study. Am J Psychiatry. Published online 2009. doi:10.1176/appi.ajp.2009.08121849

6. Hawes MT, Carlson GA, Finsaas MC, Olino TM, Seely JR, Klein DN. Dimensions of irritability in adolescents: Longitudinal associations with psychopathology in adulthood. Psychol Med. Published online 2019. doi:10.1017/S0033291719002903

7. Copeland WE, Shanahan L, Egger H, Angold A, Costello EJ. Adult diagnostic and functional outcomes of DSM-5 disruptive mood dysregulation disorder. Am J Psychiatry. Published online 2014. doi:10.1176/appi.ajp.2014.13091213

8. Vidal-Ribas P, Brotman MA, Valdivieso I, Leibenluft E, Stringaris A. The Status of Irritability in Psychiatry: A Conceptual and Quantitative Review. J Am Acad Child Adolesc Psychiatry. Published online 2016. doi:10.1016/j.jaac.2016.04.014 
9. Wakschlag LS, Estabrook R, Petitclerc A, et al. Clinical Implications of a Dimensional Approach: The Normal:Abnormal Spectrum of Early Irritability. J Am Acad Child Adolesc Psychiatry. Published online 2015. doi:10.1016/j.jaac.2015.05.016

10. Wiggins JL, Briggs-Gowan MJ, Estabrook R, et al. Identifying Clinically Significant Irritability in Early Childhood. J Am Acad Child Adolesc Psychiatry. Published online 2018. doi:10.1016/j.jaac.2017.12.008

11. Perlman SB, Jones BM, Wakschlag LS, Axelson D, Birmaher B, Phillips ML. Neural substrates of child irritability in typically developing and psychiatric populations. Dev Cogn Neurosci. Published online 2015. doi:10.1016/j.den.2015.07.003

12. Dougherty LR, Schwartz KTG, Kryza-Lacombe M, Weisberg J, Spechler PA, Lee Wiggins J. Preschool- and School-Age Irritability Predict Reward-Related Brain Function. J Am Acad Child Adolesc Psychiatry. Published online 2018. doi:10.1016/j.jaac.2018.03.012

13. Li Y, Grabell AS, Wakschlag LS, Huppert TJ, Perlman SB. The neural substrates of cognitive flexibility are related to individual differences in preschool irritability: A fNIRS investigation. Dev Cogn Neurosci. Published online 2017. doi:10.1016/j.den.2016.07.002

14. Dougherty LR, Smith VC, Bufferd SJ, et al. Preschool irritability: Longitudinal associations with psychiatric disorders at age 6 and parental psychopathology. J Am Acad Child Adolesc Psychiatry. Published online 2013. doi:10.1016/j.jaac.2013.09.007

15. Dougherty LR, Smith VC, Bufferd SJ, Kessel E, Carlson GA, Klein DN. Preschool irritability predicts child psychopathology, functional impairment, and service use at age nine. J Child Psychol Psychiatry Allied Discip. Published online 2015. doi:10.1111/jcpp.12403 
16. Costello EJ, Copeland W, Angold A. Trends in psychopathology across the adolescent years: What changes when children become adolescents, and when adolescents become adults? J Child Psychol Psychiatry Allied Discip. 2011;52(10):1015-1025. doi:10.1111/j.1469-7610.2011.02446.x

17. Evans SC, Burke JD, Roberts MC, et al. Irritability in child and adolescent psychopathology: An integrative review for ICD-11. Clin Psychol Rev. Published online 2017. doi:10.1016/j.cpr.2017.01.004

18. Humphreys KL, Schouboe SNF, Kircanski K, Leibenluft E, Stringaris A, Gotlib IH. Irritability, Externalizing, and Internalizing Psychopathology in Adolescence: CrossSectional and Longitudinal Associations and Moderation by Sex. J Clin Child Adolesc Psychol. 2019;48(5):781-789. doi:10.1080/15374416.2018.1460847

19. Cyranowski JM, Frank E, Young E, Shear MK. Adolescent onset of the gender difference in lifetime rates of major depression. A theoretical model. Arch Gen Psychiatry. Published online 2000. doi:10.1001/archpsyc.57.1.21

20. Dougherty LR, Tolep MR, Bufferd SJ, et al. Preschool Anxiety Disorders: Comprehensive Assessment of Clinical, Demographic, Temperamental, Familial, and Life Stress Correlates. J Clin Child Adolesc Psychol. Published online 2013. doi:10.1080/15374416.2012.759225

21. Olino TM, Klein DN, Dyson MW, Rose SA, Durbin CE. Temperamental emotionality in preschool-aged children and depressive disorders in parents: Associations in a large community sample. J Abnorm Psychol. Published online 2010. doi:10.1037/a0020112

22. Klein DN, Finsaas MC. The Stony Brook Temperament Study: Early Antecedents and Pathways to Emotional Disorders. Child Dev Perspect. Published online 2017. 
doi:10.1111/cdep. 12242

23. Hollingshead A. Four factor index of social status. Yale J Sociol. Published online 1975.

24. Egger HL, Erkanli A, Keeler G, Potts E, Walter BK, Angold A. Test-retest reliability of the Preschool Age Psychiatric Assessment (PAPA). J Am Acad Child Adolesc Psychiatry. Published online 2006. doi:10.1097/01.chi.0000205705.71194.b8

25. Kaufman J, Birmaher B, Brent D, et al. Schedule for Affective Disorders and Schizophrenia for School-Age Children-Present and Lifetime Version (K-SADS-PL): initial reliability and validity data. $J$ Am Acad Child Adolesc Psychiatry, 36 (1997), pp. $980-988,10.1097 / 00004583-199707000-00021$

26. Kovacs M. Children's Depression Inventory 2nd Edition (CDI2). Multi-Health Systems Inc.; 2010.

27. Birmaher B, Brent DA, Chiappetta L, Bridge J, Monga S, Baugher M. Psychometric properties of the screen for child anxiety related emotional disorders (SCARED): A replication study. J Am Acad Child Adolesc Psychiatry. Published online 1999. doi:10.1097/00004583-199910000-00011

28. Shaffer D, Gould MS, Brasic J, Fisher P, Aluwahlia S, Bird H. A Children's Global Assessment Scale (CGAS). Arch Gen Psychiatry. Published online 1983. doi:10.1001/archpsyc. 1983.01790100074010

29. Rudolph KD, Hammen C. Age and gender as determinants of stress exposure, generation, and reactions in Youngsters: A transactional perspective. Child Dev. Published online 1999. doi:10.1111/1467-8624.00048

30. Finsaas MC, Kessel EM, Dougherty LR, et al. Early Childhood Psychopathology Prospectively Predicts Social Functioning in Early Adolescence. J Clin Child Adolesc 
Psychol. Published online 2020. doi:10.1080/15374416.2018.1504298

31. Klein DN, Glenn CR, Kosty DB, Seeley JR, Rohde P, Lewinsohn PM. Predictors of first lifetime onset of major depressive disorder in young adulthood. $J$ Abnorm Psychol.

Published online 2013. doi:10.1037/a0029567

32. Petersen AC, Crockett L, Richards M, Boxer A. A self-report measure of pubertal status: Reliability, validity, and initial norms. J Youth Adolesc. Published online 1988. doi:10.1007/BF01537962

33. Grabell AS, Li Y, Barker JW, Wakschlag LS, Huppert TJ, Perlman SB. Evidence of NonLinear Associations between Frustration-Related Prefrontal Cortex Activation and the Normal:Abnormal Spectrum of Irritability in Young Children. J Abnorm Child Psychol. 2018;46(1):137-147. doi:10.1007/s10802-017-0286-5

34. Leibenluft E, Cohen P, Gorrindo T, Brook JS, Pine DS. Chronic versus episodic irritability in youth: A community-based, longitudinal study of clinical and diagnostic associations. J Child Adolesc Psychopharmacol. Published online 2006. doi:10.1089/cap.2006.16.456

35. Beauchaine TP, Constantino JN. Redefining the endophenotype concept to accommodate transdiagnostic vulnerabilities and etiological complexity. Biomark Med. Published online 2017. doi:10.2217/bmm-2017-0002

36. Kessel EM, Meyer A, Hajcak G, et al. Transdiagnostic factors and pathways to multifinality: The error-related negativity predicts whether preschool irritability is associated with internalizing versus externalizing symptoms at age 9. Dev Psychopathol. Published online 2016. doi:10.1017/S0954579416000626

37. Kessel EM, Frost A, Goldstein BL, et al. Developmental pathways from preschool 
irritability to multifinality in early adolescence: The role of diurnal cortisol. Psychol Med. Published online 2019. doi:10.1017/S0033291719003684

38. Klein DN, Shankman SA, Lewinsohn PM, Seeley JR. Subthreshold depressive disorder in adolescents: Predictors of escalation to full-syndrome depressive disorders. $J$ Am Acad Child Adolesc Psychiatry. Published online 2009. doi:10.1097/CHI.0b013e3181a56606

39. Copeland WE, Shanahan L, Costello EJ, Angold A. Childhood and adolescent psychiatric disorders as predictors of young adult disorders. Arch Gen Psychiatry. Published online 2009. doi:10.1001/archgenpsychiatry.2009.85

40. De Los Reyes A, Augenstein TM, Wang M, et al. The validity of the multi-informant approach to assessing child and adolescent mental health. Psychol Bull. Published online 2015. doi: $10.1037 / \mathrm{a} 0038498$

41. Kim JH, Chan YF, McCauley E, Vander Stoep A. Parent-Child Discrepancies in Reporting of Child Depression in Ethnic Groups. J Nurse Pract. 2016;12(6):374-380. doi:10.1016/j.nurpra.2016.01.018

42. Luby JL, Whalen D, Tillman R, Barch DM. Clinical and Psychosocial Characteristics of Young Children With Suicidal Ideation, Behaviors, and Nonsuicidal Self-Injurious Behaviors. J Am Acad Child Adolesc Psychiatry. Published online 2019. doi:10.1016/j.jaac.2018.06.031

43. Pickles A, Aglan A, Collishaw S, Messer J, Rutter M, Maughan B. Predictors of suicidality across the life span: The Isle of Wight study. Psychol Med. Published online 2010. doi:10.1017/S0033291709991905

44. Orri M, Galera C, Turecki G, et al. Pathways of Association Between Childhood Irritability and Adolescent Suicidality. J Am Acad Child Adolesc Psychiatry. Published 
online 2019. doi:10.1016/j.jaac.2018.06.034

45. Biederman J, Ball SW, Monuteaux MC, et al. New insights into the comorbidity between ADHD and major depression in adolescent and young adult females. $J$ Am Acad Child Adolesc Psychiatry. Published online 2008. doi:10.1097/CHI.0b013e31816429d3

46. Stoddard J, Stringaris A, Brotman MA, Montville D, Pine DS, Leibenluft E. Irritability in child and adolescent anxiety disorders. Depress Anxiety. Published online 2014. doi:10.1002/da.22151

47. Carlson GA, Klein DN. Commentary: Frying pan to fire? Commentary on Stringaris et al. (2018). J Child Psychol Psychiatry Allied Discip. 2018;59(7):740-743. doi:10.1111/jcpp. 12873

48. Silver J, Carlson GA, Olino TM, et al. Differential Outcomes of Tonic and Phasic Irritability in Adolescent Girls. J Child Psychol Psychiatry. In press.

49. Kotov R, Krueger RF, Watson D, et al. The Hierarchical Taxonomy of Psychopathology (HiTOP): A Dimensional Alternative to Traditional Nosologies. Association. 2017;126(4):454-477. doi:10.1037/abn0000258 


\section{Supplemental Information}

\section{Specificity Analyses: Early Childhood Risk Factors}

\section{Methods}

Parental Depression History. At the age three assessment, children's biological parents were interviewed using the Structured Clinical Interview for DSM-IV non-patient version (SCID-NP). ${ }^{1}$ Interviews were conducted by masters-level clinicians over the phone. 149 mothers and 78 fathers had a lifetime history of depression based on the SCID. A lifetime history of parental depression was coded as present if either parent had a lifetime history of depression $(n=191,42.2 \%)$. Inter-rater reliability based on 30 audiotaped interviews was excellent (Kappa=.93 for any depressive disorder).

Parental Hostility. Parents completed a modified version of the Teaching Tasks battery ${ }^{2}$ at the age three assessment. This battery consisted of six standardized tasks (book reading, naming objects with wheels, block building, matching shapes, completing a maze using an Etch A Sketch [Spin Master, Toronto, Ontario, Canada] drawing toy, and receiving a gift) designed to elicit different parent and child behaviors and interaction styles. Parental hostility captures a parent's expression of anger, frustration, and criticism toward the child. Ratings were based on a 5-point scale, ranging from "very low hostility" to "very high hostility" for each task and then averaged across tasks. The internal consistency $(\alpha=.76)$ and interrater reliability $(\mathrm{ICC}=.83$, $\mathrm{n}=55)$ of the hostility scale were acceptable.

Early Childhood Sleep Problems. The PAPA ${ }^{3}$ assesses a number of childhood sleeprelated problems (e.g., nightmares, difficult to rouse). Following guidelines from Dougherty et al., ${ }^{4} 7$ items were dichotomously rated as present or absent and summed to create a total sleep 
problems scale $(\mathrm{ICC}=.99, \mathrm{n}=21)$. The scale consists only of items that did not overlap with items used to derive diagnoses.

Child Temperament. Children completed the Laboratory Temperament Assessment Battery (Lab-TAB), ${ }^{5}$ a set of standardized tasks selected to elicit a range of temperamentrelevant behaviors and emotions. Behaviors were videotaped for observational coding and ratings were computed to form composite scores based on facial, bodily, and vocal responses. Negative emotionality (NE) consisted of the sum of the standardized total sadness, fear, and anger variables while positive emotionality (PE) consisted of the sum of the standardized positive affect and interest/engagement variables. Coding procedures are described extensively elsewhere. ${ }^{6}$ The internal consistency (Cronbach alpha) for NE and PE were .74 and .82; the ICC for interrater reliability $(n=35)$ was .82 and .89 , respectively.

\section{Results}

All longitudinal associations between preschool irritability and adolescent outcomes remained significant after adjusting for parental lifetime depression, parental hostility, child temperament, and child sleep problems (assessed at age 3), although two associations became marginally significant. The association between preschool irritability and youth-reported physical health became marginally significant $(p=.05)$ when child negative emotionality was included as an additional covariate; the association between preschool irritability and adolescent ADHD became a trend-level association $(p=.08)$ when preschool sleep problems was included as an additional covariate. Moreover, additional findings emerged: the association between preschool irritability and adolescent psychiatric service use became significant with the addition of child positive emotionality and parental hostility as covariates $(p=.046$ and $p=.038$, 
respectively), and the association between preschool irritability and paternal-reported SCARED at age 15 became significant $(p=.041)$ after adjusting for parental hostility.

Table S1: Irritability at Age 3 as Predictor of Psychiatric Disorders at Ages 12 and 15

\begin{tabular}{lcc}
\hline & \multicolumn{2}{c}{ Age 3 Irritability } \\
\hline Age 12 Psychiatric & \multicolumn{3}{c}{ Not adjusted } \\
Disorder & OR & $\mathbf{9 5 \%}$ CI \\
Depressive Disorder & .80 & $.49-1.29$ \\
Anxiety Disorder & $1.29^{*}$ & $1.05-1.59$ \\
ADHD & $1.31^{*}$ & $1.05-1.64$ \\
DBD & $2.01^{* * *}$ & $1.48-2.72$ \\
Age 15 Psychiatric & & \\
Disorder & & $.76-1.36$ \\
Depressive Disorder & 1.01 & $1.07-1.67$ \\
Anxiety Disorder & $1.34^{*}$ & $1.09-1.73$ \\
ADHD & $1.37^{* *}$ & $1.15-2.28$ \\
DBD & $1.62^{* *}$ & \\
\hline
\end{tabular}

Note: $\mathrm{ADHD}=$ attention-deficit/hyperactivity disorder; $\mathrm{CI}=$ Confidence Interval; $\mathrm{DBD}=$ disruptive behavior disorder. ${ }^{\dagger} p<.10 ; * p<.05 ; * * p<.01 ; * * * p<.001$. 


\section{Supplemental References}

1. First MB, Spitzer RL, Gibbon M, Williams JBW. Structured Clinical Interview for DSMIV-TR Axis I Disorders, Research Version, Patient Edition. SCID-I/P New York, NY, USA; 2002.

2. Egeland B, Weinfield N, Hiester M, et al. Teaching tasks administration and scoring manual. Univ Minnesota. Published online 1995.

3. Egger HL, Erkanli A, Keeler G, Potts E, Walter BK, Angold A. Test-retest reliability of the Preschool Age Psychiatric Assessment (PAPA). J Am Acad Child Adolesc Psychiatry. Published online 2006. doi:10.1097/01.chi.0000205705.71194.b8

4. Dougherty LR, Tolep MR, Bufferd SJ, et al. Preschool Anxiety Disorders: Comprehensive Assessment of Clinical, Demographic, Temperamental, Familial, and Life Stress Correlates. J Clin Child Adolesc Psychol. Published online 2013. doi:10.1080/15374416.2012.759225

5. Goldsmith HH, Reilly J, Lemery KS, Longley S, Prescott A. Laboratory temperament assessment battery: Preschool version. Unpubl Manuscr. Published online 1995.

6. Olino TM, Klein DN, Dyson MW, Rose SA, Durbin CE. Temperamental emotionality in preschool-aged children and depressive disorders in parents: Associations in a large community sample. J Abnorm Psychol. Published online 2010. doi:10.1037/a0020112 